\title{
CUNOMYIA, A DISTINCTIVE NEW HILARINE FLY GENUS FROM THE TASMANIAN WORLD HERITAGE AREA (DIPTERA: EMPIDIDAE)
}

\author{
by Daniel J. Bickel \\ (with two text figures)
}

\begin{abstract}
BiCKel, Daniel J., 1998 (31:xii): Cunomyia, a distinctive new hilarine fly genus from the Tasmanian World Heritage Area (Diptera: Empididae). Pap. Proc. R. Soc. Tasm. 132: 59-63. https://doi.org/10.26749/rstpp.132.59

ISSN 0080-4703.Entomology Section, Australian Museum, 6 College Street, Sydney South, NSW, Australia 2000.
\end{abstract}

Cunomyia unica gen. \& sp. nov. (Diptera: Empididae: Empidinae: Hilarini) is described from sites in western Tasmania. This monotypic genus is distinguished from other genera in the tribe Hilarini by the following combination of characters: vein $\mathrm{R}_{4+5}$ unbranched, $\mathrm{Sc}$ incomplete, terga 7 and 8 not reduced or modified, so that the hypopygium is positioned upright at $\epsilon$ nd of abdomen, not lying forward, and the male cercus divided into a cercal plate and digitiform clasping section. Cunomyia is considered primitive with respect to other Hilarini, on the basis of its clasping cercus and postabdominal structure.

Keywords: Cunomyia, Diptera, Empididae, Hilarini, morphology, Tasmania.

\section{INTRODUCTION}

Throughout the world, flies of the tribe Hilarini (Diptera: Empididae: Empidinae) can be seen flying back and forth above the surface of ponds, lakes and streams. This low, cruising flight is a type of aerial swarming conducted by males to attract mates. Morphologically, the most readily observable character of the Hilarini is the enlarged basitarsus on the male foreleg, which produces silk for wrapping prey or debris to present as "nuptial gifts" to females (Eltringham 1928).

The Tasmanian Hilarini are poorly known, with only 11 described species. Nine of these were described in White's 1916 paper, a work that currently serves as the basic taxonomic reference for the entire Australian fauna (White 1917). However, the Tasmanian fauna, like that of other southern temperate regions, is very rich, and more than 100 species have been separated from collections. These will be treated in future revisions of the entire Australian fauna (also see Bickel 1996).

The present paper describes a distinctive new hilarine genus, Cunomyia, from montane sites in western Tasmania, almost all of which are in the Tasmanian World Heritage Area.

\section{MATERIALS AND METHODS}

Morphological terminology follows McAlpine (1981) except for that of the male terminalia, which is based on Cumming et al. (1995). Measurements are in millimetres and were made on representative dry specimens. The position of features on elongate structures, such as leg segments, is given as a fraction of the total length, starting from the base. The relative lengths of the podomeres are representative ratios and not measurements, and are presented in the following formula and punctuation: trochanter + femur; tibia; tarsomere $1 / 2 / 3 / 4 / 5$.

The following abbreviations and terms are used: MSSC - Male secondary sexual character(s), the nongenitalic characters found only on male body; I, II, III - pro-, meso-, metathoracic legs; C - coxa; T - tibia; F - femur; ac - acrostichal setae; ad - anterodorsal; av anteroventral; $\mathrm{dc}$ - dorsocentral setae; $\mathrm{dv}$ - dorsoventral; $\mathrm{pd}$ - posterodorsal; $\mathrm{pv}$ - posteroventral; $\mathrm{t}$ - tarsus; $\mathrm{t}_{1-5}-$ tarsomeres 1 to 5 . Institutional abbreviations are as follows: Australian Museum, Sydney (AMS); Australian National Insect Collection, CSIRO, Canberra (ANIC); Illinois Natural History Survey, Urbana, Illinois (INHS); Museum of Victoria, Melbourne (MVM).

\section{Genus Cunomyia gen. $\mathrm{n}$.}

Etymology

Cunomyia is a combination of the Latin "cuna", meaning cradle, and "myia", Greek for fly, referring to the type locality in Cradle Valley, Tasmania. The gender is feminine.

Type species

Cunomyia unica sp. n. (fig. 1).

Diagnosis

Rather large, black flies; body length $7.0-8.0 \mathrm{~mm}$.

Head: ocellar triangle on raised spheroidal mound totally separating vertex from frons; frons narrower than ocellar triangle, with 7-8 short hairs along lateral margins; palp straight and strap-like; scape and pedicel setose (fig. 2A); first flagellomere conical, tapering, with short 2-articulated apical style, but without apical spine.

Thorax: mesonotum anteriad of posterior slope covered with field of uniform short setae obscuring the distinction between setal rows, except for the 3-4 longer posterior $\mathrm{dc}$ setae bordering mesonotal depression; laterotergite bare of setae; scutellum with 4-5 pairs of marginal setae.

Legs: TI with anteroapical comb of 8-10 short, even setae; male $\mathrm{It}_{1}$ distinctly swollen with dense ventral vestiture (MSSC); FII and FIII with anterior, av, and posterior subapical setae.

Wing: broad with well-developed anal lobe; costa circumambient, although narrowing markedly past vein $M_{1}$ at wing apex, and reduced in thickness along posterior 


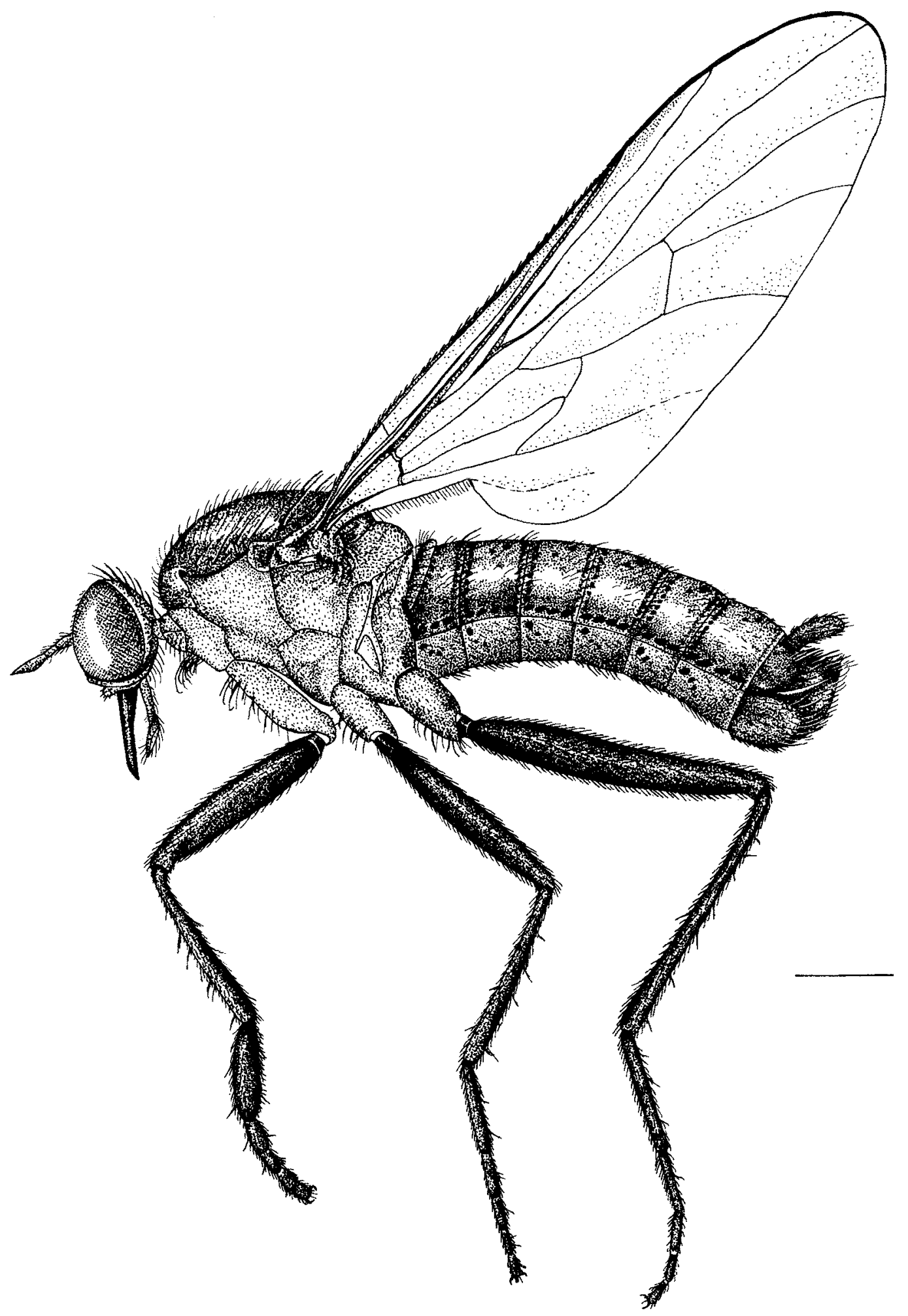

FIG. 1 - Cunomyia unica, male, habitus. Scale line $=1.0 \mathrm{~mm}$. 

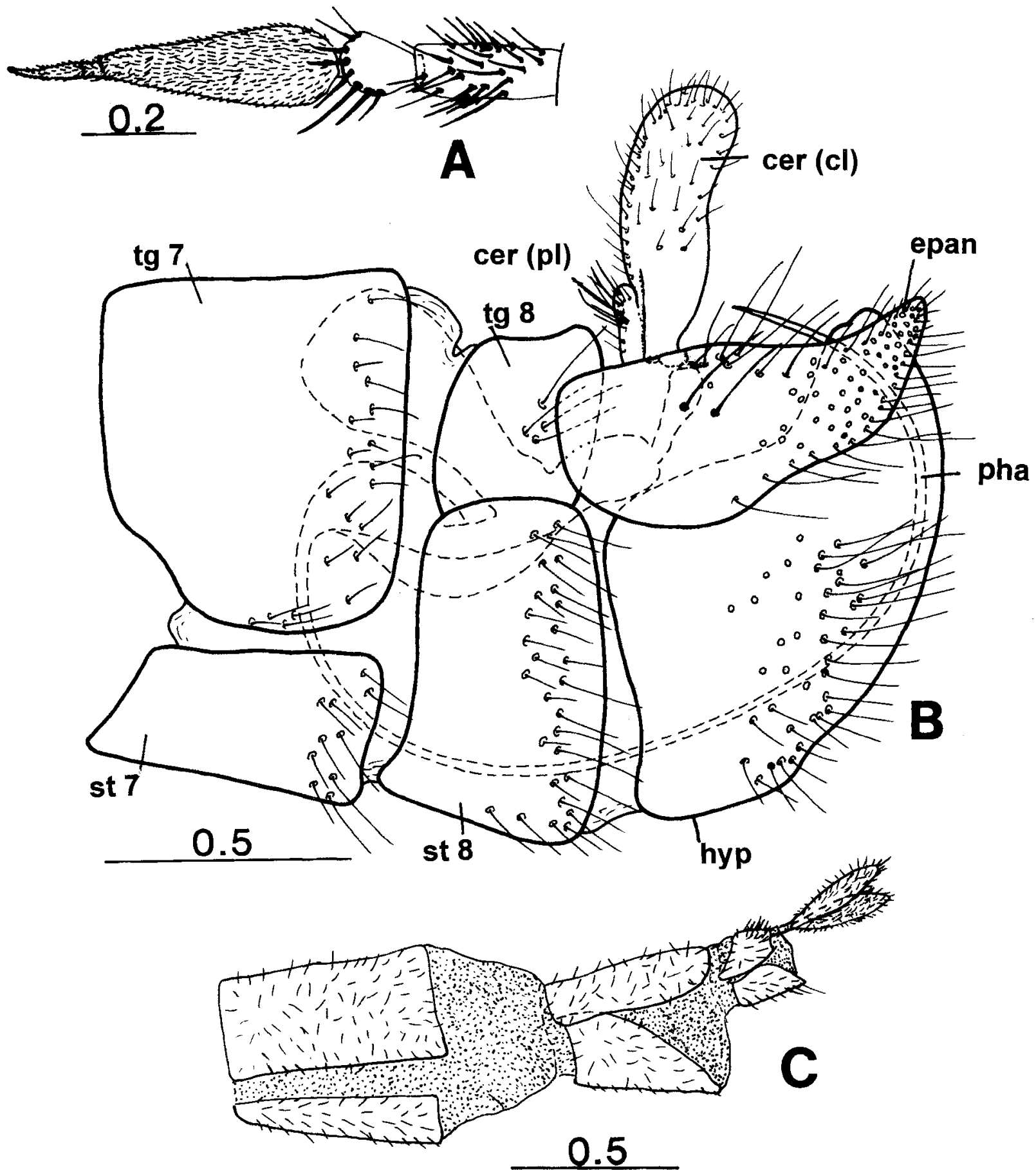

FIG. 2 - Cunomyia unica: (A) male antenna, left lateral. (B) bypopygium, left lateral. (C) female oviscapt, left lateral. Legend: cer (cl) - clasping cercus; cer (pl) - cercal plate; epan - epandrium; pha - phallus; tg - tergum; st - sternum.

wing margin; Sc incomplete; $\mathrm{R}_{1}$ distally swollen near join with costa; $\mathrm{R}_{4+5}$ unbranched; $\mathrm{CuA}$, which closes cell cup, strongly recurrent.

Abdomen: both terga 7 and 8 well developed, so that hypopygium positioned upright at end of abdomen, not flexed forward (fig. 2B); sternum 8 not ventrally supporting hypopygium; male cercus divided into short basal cercal plate and digitiform clasping cercus; hypandrium keel-like; phallus elongate and conforming to hypandrium; abdomen telescoping; oviscapt relatively unmodified, with welldeveloped terga and sterna on segments $8-10$, and with apical blade-like cerci (fig. 2C).

\section{Remarks}

Cunomyia is a monotypic genus known only from Tasmania. It possesses the following characters, which clearly place it in the tribe Hilarini (Bickel 1996): laterotergite bare, tibia I with anteroapical comb of $8-10$ short setae, male basitarsus I enlarged or swollen, hypandrium forming a curved convex hood over the phallus, costa circumambient, but reduced in thickness along posterior margin, vein $\mathrm{R}_{1}$ distinctly swollen before it joins the costa.

Cunomyia is distinguished from other hilarine genera by the following combination of characters: vein $R_{4+5}$ unbranched, Sc incomplete, terga 7 and 8 not reduced or 
modified, so that hypopygium is positioned upright at end of abdomen, not lying forward, and male cercus divided into short basal plate and a longer digitiform clasping section. The morphological and phylogenetic significance of the unmodified abdominal terga and the divided cercus will be discussed below. However, it should be noted that Cunomyia is distinctive and somewhat isolated within the Hilarini. Its relationships are unclear and, although it is only known from Tasmania, it is not necessarily most closely related to other Gondwanan taxa.

Two other genera in the Hilarini also have $R_{4+5}$ unbranched:

(1) Atrichopleura Bezzi includes described species from South Africa, South America, New Zealand (although both Collin [1933] and Smith [1969] suggested that the two New Zealand species might represent a distinct genus), and undescribed species from Australia. Many Australian species have a short and somewhat curved proboscis. Atrichopleura has well defined ac and dc setae and a hypopygium flexed over the postabdomen, so that both terga 7 and 8 are somewhat reduced in sizc. By comparison, Cunomyia has a large field of short, undifferentiated thoracic setae and an erect hypopygium, with unmodified terga 7 and 8 .

(2) Hybomyia Plant is known from a single New Zealand species. In this genus, both veins $\mathrm{R}_{4+5}$ and $\mathrm{M}$ are unbranched. As well, the proboscis is short and the thorax has welldefined ac and dc setae (Plant 1995).

\section{Cunomyia unica sp. $\mathrm{n}$. (figs 1,2)}

\section{Type material}

Holotype, O*, paratypes, O, ૧; Tasmania: Cradle Valley, 13.i.1923, A. Tonnoir; Paratypes, Oo, samébut 10.i.1923; same but 23.i.1923 (ANIC).

\section{Additional material}

Tasmania: 31 o, 6 \%, $11 \mathrm{~km}$ WSW of Daisy Dell, Cradle Mt-Lake St Clair Natl Park, 950 m, malaise trap, 1-8.i.1992 (INHS); O, Pelion Hut, $3 \mathrm{~km} \mathrm{~S} \mathrm{of} \mathrm{Mt} \mathrm{Oakleigh,}$ 41.50'S 146.03'E, 860 m. 30.xi.1990-8.i.1991, malaise trap; $0,21 \mathrm{~km} \mathrm{~S}$ of Wilmot, $650 \mathrm{~m}, 30.1 .1967 ; 0$, Hartz Mountains, 9.xii.1922; 3 ơ, Mt Field Natl Park, 18-21.xii.1922, 21.i.1949; O, Mt Field Natl Park, Lake Dobson, 22.i.1948 (ANIC); 2 đ, 2 \%, Mt Field Natl Park, Wombat Moor, 42.41'S 146.37'E, 1090 m, alpine herbfield, 25.i.1989, yellow pans; $O^{*}$, Pencil Pine $\mathrm{Ck}, \mathrm{N}$ of Cradle Mt, 41.38'S 145.54'E, $800 \mathrm{~m}$, montane forest, 30.i.1989, yeflow pans; O, Hanson Peak, nr Cradle Mt, 1200 m, 30.i.1989, alpine herbfield (AMS); 3 \%, Hastings Caves, Hot Springs $\mathrm{Ck}, 14 . x i .1972$, at light (MVM).

\section{Description}

Male: length: 7.0-7.8; wing: 5.7-6.0 × 2.3 (fig. 1); large black empidid flies, with black setae unless otherwise noted; characters noted in generic description are not repeated.

Head: spheroidal, with convex post-cranium; postcranium, vertex, frons, and face brown-black with some grey pruinosity; dorsal and ventral post-occiput covered with short setae; distinct row of postorbitals evident, culminating in 3-4 pairs of stronger postvertical setae; ocellar triangle with pair of long diverging ocellar setae anteriad of lateral ocelli; slightly notched laterad of antennae; face as wide as frons; palp black and setose and slightly clavate; proboscis dark brown, elongate, length about head height, and projecting ventrally; antenna (fig. 2A) black; scape about twice as long as pedicel; scape and pedicel setose; first flagellomere conical, tapering, and with short 2-articulated apical style.

Thorax: mostly black with dark metallic green reflections, pleura and humeral area covered by dense grey pruinosity; 1 postalar seta, 1 long and 1 short postsutural supra-alar setae; and 2 presutural intra-alar setae present; notopleuron with 4 strong setae among shorter hairs; postpronotum with strong posterior seta and field of $7-8$ weaker anterior setae; prothoracic collar (pronotum) with row of short setae; proepisternum with field of lateral hairs and with anterior fan of 10-12 long setae; laterotergite and remainder of pleura bare of setae; scutellum with some supernumerary setae; metanotum broad and slightly bulging.

Legs: black, but coxae covered with dense grey pruinosity and concolorous with pleura; CI with long anterior setae and hairs, and CII and CIII with stronger lateral setae; all tarsi with strong black claws and large yellowish pulvilli; I: $3.5 ; 3.7 ; 1.5 / 0.5 / 0.3 / 0.2 / 0.4$; FI with only short vestiture; TI with $3-4$ pairs of short ad-pd setae, and anteroapical comb of $8-10$ short, even setae; II: $3.6 ; 3.0 ; 1.5 /$ $0.7 / 0.4 / 0.2 / 0.5$; FII with short vestiture and with stronger anterior, av, and posterior subapical setae; TII with 4-5 irregular ad-pd setal pairs, and some short ventral setae along length; III: 5.5; 4.7; 2.0/ 1.2/ 0.7/ 0.4/ 0.6; FIII with short hairs and with stronger subapical anterior, posterior, av and pv setae; TIII with 7-8 irregular ad-pd setal pairs, and some short ventral setae; IIIt, with 1-2 short dorsal setae.

Wing: membrane smoky; costa demelanised along posterior wing margin; brownish stigma present under distal $R_{1}$; costa haired, but other veins bare; $A_{1}$ present distally only as weak fold; $A_{2}$ present only as trace; anal angle well developed; lower calypter yellowish with yellow setae; halter yellow.

Abdomen: dark brown-black, and covered with grey pruinosity and black vestiture; terga with only moderately long setae along posterior margins; each tergum of preabdomen with four oblong depressions or abdominal plaques on lateral margin, with additional depressions on corresponding sterna; segment 7 with well-developed tergum and sternum, not differentiated from segments anteriad; tergum 8 only slightly reduced; sternum 8 unmodified; hypopygium (fig. 2B). Phallus along with oblong sperm pump internally extending into abdominal segments 7 and 8; epandrium setose, and distinct surstylus not evident.

Fernale: similar to male except as noted: frons wider, such that ocellar triangle not adjoining eyes; face and clypeus both wider; $\mathrm{It}_{1}$ not swollen; oviscapt (fig. $2 \mathrm{C}$ ).

\section{Remarks}

Cunomyia unica is known from late November to early February in western Tasmania. It has been collected in malaise traps, yellow pans, at light, and swept from vegetation in a variety of montane habitats, including streams in subalpine woodland, and alpine lakes, heath and herbfields. Its behaviour and swarming activity are unknown. The specific epithet unica refers to the genus currently comprising a unique species. 


\section{MORPHOLOGICAL NOTES}

Two morphological characters of Cunomyia require further discussion.

\section{(1) Cercus}

In most members of the tribe Hilarini, the male cercus (= dorsal lamella in Chvála 1983) is rather small and desclerotised, and fused laterally with the surstylus (= bacilliform sclerite of Cumming \& Sinclair) and epandrium (J. Cumming $\&$ B. Sinclair, pers. comm.). The cercus in the tribe Empidini, on the other hand, is often enlarged and functions as a clasping organ.

Cunomyia has an enlarged sclerotised male cercus, which is divided in to a distinctive digitiform "clasping cercus" and smaller "cercal plate" (fig. 2B). Sinclair (1995) discussed a similar division of the cercus in the subfamily Clinocerinae, and considered this character state to be a synapomorphy for a major clade within that subfamily. Further, he noted that, although the male cercus is modified for clasping in the ground plan of the clade (Empidinae + Hemerodrominae), it remains undivided. Also, the clasping cercus of Cunomyia is erect while that of most Empidinae lies horizontally (B. Sinclair, pers. comm.). Therefore, the distinctly divided cercus in Cunomyia is seen as an independent development or homoplasy with the subfamily Clinocerinae. [Here it must be noted that the median surface of the clasping cercus in Clinocerinae has modified hairs (Sinclair 1995), which are absent on Cunomyia.] Possibly Cunomyia is basal within the Hilarini, sharing a clasping cercus with its sister group, the Empidini, but became divided secondarily in the genus.

\section{(2) Male postabdomen}

Most Hilarini have abdominal segments 2-6 with welldeveloped terga and sterna, while terga 7 and 8 are either reduced in size and/or partially desclerotised to allow the hypopygium to be flexed anteriorly. This is often marked by a distinct narrowing and flattening of the male postabdomen anteriad of the hypopygium.

By contrast, in Cunomyia abdominal segment 7 is well developed and subequal with the pre-abdominal segments, and segment 8 is only slightly reduced in size but retains a well-sclerotised tergum. As a result, the Cunomyia hypopygium is unflexed and confined to the end of the abdomen, held in place by the collar-like segments 7 and 8 (figs 1,2A). I have not seen other Hilarini with this structure, and regard this as a primitive condition. These two related characters can be stated in the following formula:

Character: plesiomorphic (ancestral) state; apomorphic (derived) state.

(1) Abdominal terga 7 and 8: well-developed, sclerotised, collar like; reduced in size, desclerotised, and/ or flattened. (2) Hypopygium: erect, unflexed and confined to end of abdomen; flexed anteriorly over terga 7 and 8 .

\section{SYSTEMATIC POSITION OF CUNOMYIA}

Cunomyia is therefore presumed to be primitive with respect to other Hilarini in its clasping cercus and postabdominal structure. However, the entire tribe needs considerable redefinition at the generic level before its phylogenetic position can be ascertained.

\section{ACKNOWLEDGEMENTS}

I thank the following curators for loan of specimens: $M$. Moulds (AMS); P. Cranston (ANIC); D. Webb (INHS); K. Walker (MVM). Brad Sinclair provided valuable comments and insights on empidid morphology and systematics. Sue Bullock drew the male genitalic figure. Carmen Zurl drew the habitus of Cunomyia unica. This research was supported by Australian Research Council grant A19232651, for study of the systematics of Australian Empidinae.

\section{REFERENCES}

Bickel, D.J., 1996: Thinempis, a new genus from Australia and New Zealand (Diptera: Empididae), with notes on the tribal classification of the Empidinae. Syst. Entomol. 21: 115-128.

ChVÁlA, M., 1983: The Empidoidea (Diptera) of Fennoscandia and Denmark II. General Part. The Families Hybotidae, Atelestidae, and Microphoridae. Fauna Entomol. Scand. 12: $1-279$.

Collin, J.E., 1933: Empididae, Part 4. DIPTERA OF PATAGONIA AND SOUTH CHILE. British Museum (Natural History), London: $334 \mathrm{pp}$.

Cumming, J.M., Sinclair, B.J. \& Wood, D.M., 1995: Homology and phylogenetic implications of male genitalia in Diptera - Eremoneura. Entomol. Scand. 26: 120-151.

Eltringham, H., 1928: On the production of silk by species in the genus Hilara Meig. Proc. R. Soc. Lond. (B) 102: $122-$ 135.

MCAlpine, J.F., 1981: Morphology and terminology. In McAlpine, J.F. et al.: MANUAL OF NEARCTIC DIPTERA, VOL. 1. Agriculture Canada, Ottawa: 9-64.

Plant, A.R. 1995. A new genus of Empidinae (Diptera: Empididae). NZ Entomol. 18: 25-28.

SinClaIR, B.J., 1995: Generic revision of the Clinocerinae (Empididae), and descriprion and phylogenetic relationships of the Trichopezinae, new status (Diptera: Empidoidea). Can. Entomol. 127: 665-752.

Smith, K.G.V., 1969: The Empididae of southern Africa (Diptera). Ann. Natal Mus. 19: 1-342.

WhIte, A., 1917: The Diptera-Brachycera of Tasmania. Part II. Families Asilidae, Bombyliidae, Empidae, Dolichopodidae and Phoridae. Pap. Roy. Soc. Tasm. 1916: 148-266.

(accepted 28 September 1998) 